\title{
Physico-chemical quality attributes and fatty acid profiles of pork from Windsnyer and Large White gilts
}

\author{
J. Madzimure ${ }^{1 \#}$, M. Chimonyo ${ }^{2}$, A. Hugo ${ }^{3}$, A.G. Bakare ${ }^{4}$, C.L.F. Katiyatiya ${ }^{5} \&$ V. Muchenje ${ }^{5}$ \\ ${ }^{1}$ Chinhoyi University of Technology, Department of Animal Production and Technology, P. Bag 7724, Chinhoyi, \\ Zimbabwe \\ ${ }^{2}$ University of KwaZulu-Natal, Discipline of Animal and Poultry Science, P. Bag X01, Scottsville 3209, Pietermaritzburg, \\ South Africa; \\ ${ }^{3}$ Department of Microbial Biochemical and Food Biotechnology, University of Free State, P.O. Box 339, Bloemfontein, \\ 9300, South Africa; \\ ${ }^{4}$ Department of Agriculture and Animal Health, University of South Africa, Private Bag X6, Florida, 1710, South Africa; \\ ${ }^{5}$ University of Fort Hare, Department of Livestock and Pasture Science, P. Bag X1314, Alice 5700, South Africa
}

(Received 20 February 2016; Accepted 11 December 2016; First published online 5 January 2017)

Copyright resideswiththeauthors in termsoftheCreativeCommonsAttribution 4.0 SouthAfricanLicense.

See: http://creativecommons.org/licenses/by/4.0/za

Conditionof use: The user may copy, distribute, transmit and adaptthework, but mustrecognizetheauthors and theSouthAfricanJournalof Animal Science.

\begin{abstract}
The objective of the study was to assess the physico-chemical pork quality attributes and fatty acid profiles of indigenous Windsnyer (WS) and Large White (LW) gilts. Twelve gilts of each breed were fed similar commercial diets from weaning until slaughter at the age of 21 weeks. The $m$. longissimus thoracis et lumborum was sampled. Differences in muscle $\mathrm{pH}$ values obtained 24 hours post mortem $\left(\mathrm{pH}_{24}\right)$ were not significant in pork from the WS or LW gilts. Pork lightness 24 hours post mortem $\left(L_{24}^{*}\right)$ was significantly lower in WS gilts than in LW gilts. Muscle saturated fatty acids (SFA) were higher in WS gilts than LW gilts. Fat of LW gilts had higher polyunsaturated (PUFA), n- 6 fatty acids, $n-3$ fatty acids and PUFA: SFA ratio than WS gilts. The study showed preferential attributes of pork from LW gilts than from WS gilts. The accrued information could benefit the food industry by assisting researchers and nutritionists to interpret the quality of pork from different pig genotypes for health-conscious consumers. Furthermore, it aids in determining the concern about pork as a cardiovascular risk factor and acts as a planning tool for public-health programmes.
\end{abstract}

Keywords: Fatty acids, indigenous pigs, pork quality, tenderness

\#Corresponding author: madzimurej@gmail.com

\section{Introduction}

South Africa has about 1.6 million pigs, which are kept for the production of meat to feed the human population (FAOSTAT, 2012). Most of the pigs are reared under commercial farming practices, in which more than 150 metric tonnes of pork are produced annually (Van der Westhuizen, 2011). The most common pig breeds are the Large White, Landrace, Duroc and Pietrien (Halimani et al., 2010). Windsnyer pigs (WS), an indigenous genotype to southern Africa, do not contribute greatly to commercial pork production, because they have slow growth rates, smaller carcasses and tend to deposit fat early when fed high-energy diets (Bester, 2010; Chimonyo et al., 2010). Most of the fat is subcutaneous, can easily be trimmed (Chimonyo et al., 2005) and is used for cooking by poor farmers in rural areas. Most of these indigenous pigs are reared in rural areas of southern Africa, so they rely on scavenging, eating grasses and insects, and digging out roots. This may result in their producing less fat and could provide an opportunity to supply inorganically produced pork for a niché market.

Several studies have reported pork quality attributes of various pig breeds. Hoffman et al. (2004) reported pork quality attributes for LW and Landrace crosses. Likewise, pork quality attributes were reported in Yorkshire, Duroc and Landrace breeds in a study by Li et al. (2013). Not many attempts have been made to assess the pork quality objectively of WS pigs in southern Africa. These pigs probably produce acceptable pork compared with their counterparts (Landrace, Large White, Duroc and Pietrien) on commercial farms. The promotion of organically produced indigenous pork on the market might enhance the choices for the increasing health-conscious population. The objective of the study, therefore, was to determine the physicochemical attributes and fatty acids profiles for genetically unimproved South African indigenous WS gilts and 
improved LW gilts. It was hypothesized that there are no differences in physico-chemical attributes and fatty acid profiles between genetically unimproved South African indigenous WS gilts and improved LW gilts.

\section{Materials and Methods}

The study was conducted at Fort Cox College of Forestry and Agriculture in the province of Eastern Cape, South Africa. The experiment was managed according to procedures approved by the University of Fort Hare Ethics Committee. A total of twenty-four 6-week-old gilts were used, 12 from each of the WS and LW breeds. Their average weight at weaning was $7.4 \pm 0.59 \mathrm{~kg}$ and $9.91 \pm 0.59 \mathrm{~kg}$, respectively. The LW gilts were obtained from Fort Cox College of Agriculture and Forestry and the WS gilts were obtained from the surrounding communities. At weaning and once a month afterwards, the pigs were dosed and sprayed against gastro-intestinal parasites and ecto-parasites, respectively. Each pig was an experimental unit and they were randomly allocated to pens. The pigs were identified and housed individually in a $3 \times 2 \mathrm{~m}$ concrete floored and zinc-roofed pen. The walls of each pen were $1.5 \mathrm{~m}$. All pigs were fed a commercial feed (Monti Feeds Pvt Ltd, East London, South Africa) on an ad libitum basis. The piglets were weaned at five weeks, and were allowed to adapt to the feed for seven days. From days 35 to 56 the pigs were fed on pig weaner meal (180 g crude protein (CP)/kg, $13 \mathrm{MJ}$ metabolizable energy per $\mathrm{kg} \mathrm{DM}$. Pig grower meal $(160 \mathrm{~g} \mathrm{CP} / \mathrm{kg}$, 13.7 MJ ME/kg DM) was offered from Day 57 until Day105. The fatty acid profiles of the pig weaner meal and pig grower meal are shown in Table 1.

Table 1 Fatty acid profiles (as a percentage of total fatty acids identified) in feed given to Large White and Windsnyer gilts before slaughter

\begin{tabular}{lrc}
\hline Fatty acids & Pig weaner meal & Pig grower meal \\
\hline $14: 0$ & 0.15 & 0.09 \\
$16: 0$ & 21.26 & 16.44 \\
$16: 1 c 9$ & 0.38 & 0.13 \\
$17: 0$ & 0.71 & 0.10 \\
$18: 0$ & 5.09 & 1.77 \\
$18: 1 c 9$ & 34.23 & 24.37 \\
$18: 1 c 7$ & 1.50 & 0.80 \\
$18: 2 c 9,12(\mathrm{n}-6)$ & 32.63 & 53.30 \\
$20: 0$ & 0.48 & 0.24 \\
$18: 3 c 9,12,15(\mathrm{n}-3)$ & 2.10 & 2.46 \\
$22: 0$ & 0.31 & 0.12 \\
$20: 5 c 5,8,11,14,17(\mathrm{n}-3)$ & 0.12 & 0.11 \\
$24: 1 c 15$ & 1.05 & 0.05 \\
SFA & 28.00 & 18.77 \\
MUFA & 37.15 & 25.35 \\
PUFA & 34.85 & 55.87 \\
n-6 & 32.63 & 53.30 \\
n-3 & 2.22 & 2.57 \\
PUFA: SFA & 1.24 & 2.98 \\
n-6: $\mathrm{n}-3$ & 14.69 & 20.71 \\
& & \\
\hline
\end{tabular}

SFA: total saturated fatty acids, MUFA: total monounsaturated fatty acids, PUFA: total polyunsaturated fatty acids, n-6: total omega- 6 fatty acids, $n-3$ : total omega- 3 fatty acids, c: cis, PUFA: SFA: ratio of polyunsaturated fatty acids and saturated fatty acids, $n-6: n-3:$ ratio of $n-6: n-3$.

The slaughter of pigs was done at Adelaide Municipal abattoir, which is about $80 \mathrm{~km}$ from the study site. Pigs were transported on a cool morning, allowed to rest for an hour on arrival, and given water ad libitum. They were stunned using the electric stunning method, their jugular veins severed, fully bled and 
scalded in hot water afterwards. The carcasses were chilled at $0{ }^{\circ} \mathrm{C}$ for 24 hours. After 24 hours, a four-rib (eighth to eleventh) section of $m$. longissimus thoracis et lumborum was removed from the right side of each carcass and identified, and $\mathrm{pH}$ and colour were measured. A portable fibre-optic $\mathrm{pH}$ meter probe (Crison $\mathrm{pH}$ 25 instruments S.A., Alella, Spain) was used to measure pH. The Minolta colour guide 45/0 BYK-Gardener $\mathrm{GmbH}$ machine with a $20 \mathrm{~mm}$ diameter measurements area and illuminant D65-day light, $10^{\circ}$ standard observer was used to measure the muscle colour ( $L^{*}$ : lightness, $a^{*}$ : redness, and $b^{*}$ : yellowness). Areas of connective tissue and intramuscular fat were avoided. The $\mathrm{m}$. longissimus thoracis et lumborum sections were vacuum packed and kept frozen at $-20^{\circ} \mathrm{C}$ for two weeks before laboratory analyses. They were then thawed overnight at room temperature, and thawing loss was estimated. The muscles were cut into small pieces, placed in a water tight plastic bag and cooked for 45 minutes in a water bath at $85{ }^{\circ} \mathrm{C}$ until $70{ }^{\circ} \mathrm{C}$ internal temperature was reached. Afterwards, the samples were left to cool on a table at room temperature and weighed again. Cooking losses and shear force were determined. The backfat samples from the pig breeds were collected according to the method described by Hugo \& Roodt (2015).

Total lipid from feed material was extracted with Soxhlet extraction according to AOAC Official Method 920.39 (2005) procedures for determination of fats. Total lipid from backfat (collected on the last rib position) and muscle sample was quantitatively extracted, according to the method of Folch et al. (1957), using chloroform and methanol in a ratio of 2:1. A rotary evaporator was used to dry the fat extracts under vacuum and the extracts were dried overnight in a vacuum oven at $50{ }^{\circ} \mathrm{C}$, using phosphorus pentoxide as moisture adsorbent. Total extractable intramuscular fat was determined gravimetrically from the extracted fat and expressed as $\%$ fat $(\mathrm{w} / \mathrm{w})$ per $100 \mathrm{~g}$ tissue. The fat-free dry matter (FFDM) content was determined by weighing the residue on a pre-weighed filter paper, used for Folch extraction, after drying. By determining the difference in weight, the FFDM could be expressed as \% FFDM (w/w) per $100 \mathrm{~g}$ tissue. The moisture content of the muscle and backfat was determined by subtraction (100\% - \% lipid - \% FFDM) and expressed as \% moisture (w/w) per $100 \mathrm{~g}$ tissue. Approximately $10 \mathrm{mg}$ of extracted lipid from feed, backfat and muscle was transferred into a Teflon-lined screw-top test tube. Fatty acid methyl esters (FAME) were prepared for gas chromatography by methylation of the extracted fat, using methanol-BF3 (Christie et al., 2001). FAME from feed and muscle were quantified using a Varian GX 3400 flame ionization GC, with a fused silica capillary column, Chrompack CPSIL 88 (100 m length, $0.25 \mathrm{~mm}$ ID, $0.2 \mu \mathrm{m}$ film thickness), split ratio 100:1. Analysis was performed using an initial isothermic period $\left(40^{\circ} \mathrm{C}\right.$ for 2 minutes). Then, temperature was increased at a rate of $4{ }^{\circ} \mathrm{C} /$ minute to $230{ }^{\circ} \mathrm{C}$. Finally, an isothermic period of $230{ }^{\circ} \mathrm{C}$ for 10 minutes followed. FAME $n$ hexane $(1 \mu \mathrm{L})$ was injected into the column using a Varian $8200 \mathrm{CX}$ Autosampler. The injection port and detector were both maintained at $250^{\circ} \mathrm{C}$. Hydrogen, at $45 \mathrm{psi}$, functioned as the carrier gas, while nitrogen was employed as the makeup gas. Varian Star Chromatography software recorded the chromatograms. FAME samples were identified by comparing the retention times of FAME peaks from samples with those of standards obtained from Supelco (Supelco 37 Component Fame Mix 47885-U, Sigma-Aldrich Aston Manor, Pretoria, South Africa). Fatty acids were expressed as the proportion of each individual fatty acid to the total of all fatty acids present in the sample. The omega-3 (n-3), omega- $6(n-6)$, total saturated fatty acids (SFA), and total monounsaturated fatty acids (MUFA), polyunsaturated fatty acids (PUFA), PUFA: SFA ratio and $n-6: n-3$ ratios were computed.

The effects of pig breed on tenderness, cooking loss, thawing loss, muscle and fat moisture, fat-free dry matter, fat and fatty acid profiles were analysed using general linear model (GLM) procedures of SAS (2008). The effects of pig breed on pH and pork colour were also analysed using GLM of SAS (2008). Significant means were compared using the PDIFF option in SAS (2008).

\section{Results and Discussion}

The physico-chemical attributes of pork from WS and LW gilts are shown in Table 2. Pork from LW gilts had higher $(P<0.05)$ thawing loss and cooking loss than WS gilts. Pork from LW gilts had higher $\mathrm{L}^{*}{ }_{24}(P$ $<0.001$ ) than pork from WS gilts. Pig breed had no effect on WBSF, $\mathrm{pH}_{24}, \mathrm{a}_{24}$ and $\mathrm{b}_{24}$. There was no interaction between pig breed and time on $\mathrm{pH}$ and colour. The observed Warner Braztler shear force values for the $\mathrm{m}$. longissimus thoracis et lumborum were higher than those reported by Dilger et al. (2010). Variations in WBSF might be due to pre- and post-slaughter procedures, and instrumental differences, as reported by Van Oeckel et al. (1999). The findings that there were differences in cooking loss between pork from LW and WS gilts agree with those of Renaudeau et al. (2005), who reported lower cooking loss (30.2\%) in indigenous Creole pigs than the LW breed (33.1\%). As observed in the study, differences in cooking losses between LW and WS gilts show the LW to be more susceptible to porcine stress syndrome and to have an increased likelihood of developing pale soft exudative (PSE) meat. 
Table 2 Least square mean ( \pm standard error) values for Warner Braztler shear force, cooking loss \%, thawing loss \%, pH and colour of Large White and Windsnyer gilts

\begin{tabular}{|c|c|c|c|}
\hline \multirow{2}{*}{ Pork quality attributes } & \multicolumn{2}{|c|}{ Breed } & \multirow{2}{*}{ Significance } \\
\hline & Windsnyer $(n=12)$ & Large White $(n=12)$ & \\
\hline WBSF & $24.04 \pm 1.210$ & $22.06 \pm 1.210$ & NS \\
\hline Cooking loss \% & $25.77 \pm 0.480$ & $26.93 \pm 0.480$ & * \\
\hline Thawing loss $\%$ & $6.03 \pm 0.440$ & $7.37 \pm 0.440$ & * \\
\hline \multicolumn{4}{|l|}{$\mathrm{pH}$ values } \\
\hline $\mathrm{pH}_{24}$ & $5.56 \pm 0.070$ & $5.57 \pm 0.070$ & NS \\
\hline \multicolumn{4}{|l|}{ Colour measurements } \\
\hline$L_{24}^{*}$ & $49.74 \pm 1.240$ & $57.19 \pm 1.240$ & $* * *$ \\
\hline$a_{24}^{*}$ & $7.22 \pm 0.721$ & $6.47 \pm 0.721$ & NS \\
\hline$b_{24}^{*}$ & $9.20 \pm 0.509$ & $9.80 \pm 0.509$ & NS \\
\hline
\end{tabular}

Significance level: ${ }^{*} P<0.05,{ }^{* *} P<0.01,{ }^{* *} P<0.001$, NS: not significant.

WBSF: Warner Braztler shear force (N), $\mathrm{pH}_{24}: \mathrm{pH}$ at 24 hours' post slaughter.

$L^{*}$ value represents lightness; $a^{*}$ value represents redness; $b^{*}$ represents yellowness (numeric figures represents number of hours post slaughter).

The cooking loss of LW (26.9\%) and WS (25.8\%) pigs in the study, however, is far less than that reported for Duroc and Chinese breeds (Meshian, Fenjing, and Minzhu pigs) (Wheeler \& Young, 1992). The differences in cooking losses may be attributed to several factors, such as differences in ageing, cooking method, cooking temperatures, duration of cooking temperatures and marbling (Lawrie, 1998; Nour et al., 1994; Yu et al., 2005).

The ultimate $\mathrm{pH}\left(\mathrm{pH}_{24}\right)$ for $\mathrm{LW}$ and WS gilts in the current study was similar to that reported for LW sired pigs (Terlouw et al., 2009). Renaudeau \& Maurot (2007) reported $\mathrm{pH}_{24}$ values of 5.71 and 5.62 for the indigenous Creole and LW breeds; respectively. The acceptable $\mathrm{pH}_{24}$ range for normal meat is 5.3-5.7. Pork $\mathrm{pH}_{24}$ is responsible for the changes that take place on the muscle. In addition, $\mathrm{pH}$ has been reported to affect the colour of meat in some studies. In the current study, pork pH for both breeds was similar. Consequently, the authors cannot explain the variations in colour obtained for the two breeds in the study. These variations maybe breed dependent. According to Gentry et al. (2001), pigs are born with a predominance of Type I (darker red) fibres. As they develop, there is a shift to Type IIA and Type IIB fibres. The WS gilts, therefore, still had the predominant Type I fibres at slaughter compared with LW gilts. These observations on colour may suggest a lower incidence of PSE traits in the indigenous WS gilts (Hoffman et al., 2005).

Table 3 shows muscle proximate analysis and fatty acid profiles for WS and LW gilts. Windsnyer gilts had higher $(P<0.001)$ FFDM and SFA $(P<0.05)$ compared with LW gilts. The indigenous WS gilts also had higher $(P<0.01)$ proportions of palmitic $(16: 0)$ and arachidic acid $(20: 0)$ than LW gilts. The proportions of margaric $(17: 0)$ and behenic $(22: 0)$ acids, however, were higher $(P<0.05)$ in the muscle of LW gilts than in WS gilts. There were no breed differences in most fatty acids and their ratios, moisture content and marbling. Table 4 shows proximate analysis and fatty acid profiles for backfat in the indigenous WS and exotic LW gilts. Windsnyer gilts had higher $(P<0.05)$ extractable fat, palmitic $(16: 0)$, arachidic (20:0) and SFA than LW gilts. Large White gilts, on the other hand, had higher $(P<0.05)$ proportions of FFDM, pentadecanoic $(15: 0)$, margaric (17:0), linoleic $(18: 2 c 9,12(n-6))$, eicosatrienoic $(20: 3 c 11,14,17(n-3))$, arachidonic $(20: 4 c 5,8,11,14$ $(n-6))$, PUFA, n-6, n-3and PUFA/SFA than WS gilts. Fatty acids that were not in the feed but were found in the muscle and backfat of both breeds include arachidonic $(20: 4 c 5,8,11,14(\mathrm{n}-6))$, $\mathrm{y}$-linolenic $(18: 3 c 6,9,12(\mathrm{n}$ $6)$ ), heptadecenoic (17:1c10), elaidic (18:1 t9) and pentadecanoic. Of these fatty acids, heptadecenoic and $\mathrm{Y}$-linolenic were found only in the muscle and pentadecanoic was found in the backfat.

In both breeds, backfat and muscle fatty acids were deposited in the form that they were presented in the diet, as suggested by Wood et al. (2008). Fatty acids that were not in the feed and therefore must have been synthesised in the animal included heptadecenoic and pentadecanoic acids. Differences in fatty acid composition between breeds can be attributed to the PUFA : SFA ratio. This ratio decreases as the level of fat in the meat increases (Enser et al., 1996). The minimum recommended value for PUFA : SFA ratio is 0.4 (Muchenje et al., 2009) and the ideal ratio is 0.7 (Warnants et al., 2001). 
Table 3 Muscle proximate analysis and fatty acid profiles (as a percentage of total fatty acids identified) ( \pm standard errors) for Large White and Windsnyer gilts

\begin{tabular}{|c|c|c|c|}
\hline \multirow{2}{*}{ Attributes } & \multicolumn{2}{|c|}{ Breed } & \multirow{2}{*}{ Significance } \\
\hline & Windsnyer $(n=12)$ & Large White $(n=12)$ & \\
\hline \multicolumn{4}{|l|}{ Proximate analysis } \\
\hline Marbling & $2.61 \pm 0.207$ & $2.38 \pm 0.207$ & NS \\
\hline FFDM & $24.72 \pm 0.323$ & $22.95 \pm 0.323$ & $* * *$ \\
\hline Moisture & $72.66 \pm 4.120$ & $68.84 \pm 4.120$ & NS \\
\hline \multicolumn{4}{|l|}{ Fatty acids and ratios } \\
\hline $14: 0$ & $1.32 \pm 0.053$ & $1.31 \pm 0.053$ & NS \\
\hline $16: 0$ & $28.88 \pm 0.190$ & $28.04 \pm 0.190$ & ** \\
\hline $16: 1 c 9$ & $3.36 \pm 0.115$ & $3.39 \pm 0.115$ & NS \\
\hline $17: 0$ & $0.26 \pm 0.017$ & $0.31 \pm 0.017$ & ${ }^{*}$ \\
\hline $17: 1 c 10$ & $0.27 \pm 0.042$ & $0.28 \pm 0.042$ & NS \\
\hline $18: 0$ & $11.62 \pm 0.165$ & $11.22 \pm 0.165$ & NS \\
\hline $18: 1 t 9$ & $0.04 \pm 0.002$ & $0.05 \pm 0.002$ & NS \\
\hline $18: 1 c 9$ & $38.07 \pm 0.653$ & $38.54 \pm 0.653$ & NS \\
\hline $18: 1 c 7$ & $3.97 \pm 0.077$ & $4.19 \pm 0.077$ & NS \\
\hline $18: 2 c 9,12(n-6)$ & $9.48 \pm 0.642$ & $9.91 \pm 0.642$ & NS \\
\hline $20: 0$ & $0.14 \pm 0.006$ & $0.11 \pm 0.006$ & $* *$ \\
\hline $18: 3 c 6,9,12(n-6)$ & $0.03 \pm 0.010$ & $0.05 \pm 0.010$ & NS \\
\hline $18: 3 c 9,12,15(n-3)$ & $0.32 \pm 0.040$ & $0.36 \pm 0.040$ & NS \\
\hline $20: 2 c 11,14(n-6)$ & $0.18 \pm 0.009$ & $0.18 \pm 0.009$ & NS \\
\hline Behenic & $0.01 \pm 0.01$ & $0.03 \pm 0.01$ & NS \\
\hline 22:0 & $0.01 \pm 0.009$ & $0.03 \pm 0.009$ & * \\
\hline $20: 3 c 11,14,17(n-3)$ & $0.23 \pm 0.030$ & $0.20 \pm 0.030$ & NS \\
\hline $20: 4 c 5,8,11,14(n-6)$ & $1.81 \pm 0.220$ & $1.94 \pm 0.220$ & NS \\
\hline SFA & $42.23 \pm 0.310$ & $41.02 \pm 0.310$ & * \\
\hline MUFA & $45.72 \pm 0.713$ & $46.44 \pm 0.713$ & NS \\
\hline PUFA & $12.05 \pm 0.828$ & $12.64 \pm 0.828$ & NS \\
\hline$n-6$ & $11.49 \pm 0.825$ & $12.08 \pm 0.825$ & NS \\
\hline$n-3$ & $0.55 \pm 0.031$ & $0.56 \pm 0.031$ & NS \\
\hline PUFA:SFA & $0.29 \pm 0.022$ & $0.31 \pm 0.022$ & NS \\
\hline$n-6: n-3$ & $21.45 \pm 1.550$ & $21.66 \pm 1.550$ & NS \\
\hline
\end{tabular}

Significance level: ${ }^{*} P<0.05,{ }^{* *} P<0.01,{ }^{* * *} P<0.001$, NS: not significant.

FFDM: fat-free dry matter, SFA: total saturated fatty acids, MUFA: total monounsaturated fatty acids, PUFA: total polyunsaturated fatty acids, $n-6$ : total omega- 6 fatty acids, $n-3$ : total omega-3 fatty acids, $c$ : cis, t: trans, PUFA : SFA: ratio of polyunsaturated fatty acids and saturated fatty acids, $n-6: n-3:$ ratio of $n-6: n-3$.

This implies that muscle and backfat PUFA : SFA ratios of both breeds in the current study had lower nutritional value for consumers. The PUFA : SFA ratio for LW gilts was better than for WS gilts.

The muscle of both breeds had less n- 6 and n-3 than in backfat, in contrast to the report of Wood et al. (2008). The proportions for $n-6: n-3$ in pork of WS gilts and LW gilts were far higher than the 7.2 reported in muscle by Enser et al. (1996). This can be ascribed to the diet pigs were consuming prior to slaughter. In the study, the $n-6: n-3$ ratio was about $20: 71$ in finishing diet of pigs. This might have caused a higher $n-6: n-3$ proportion in muscle and backfat. 
Table 4 Backfat proximate analysis and fatty acid profiles (as a percentage of the total fatty acids identified) ( \pm standard errors) for Large White and Windsnyer gilts

\begin{tabular}{|c|c|c|c|}
\hline \multirow{2}{*}{ Attributes } & \multicolumn{2}{|c|}{ Breed } & \multirow{2}{*}{ Significance } \\
\hline & Windsnyer (n: 12) & Large White (n: 12) & \\
\hline \multicolumn{4}{|l|}{ Proximate analysis } \\
\hline Extractable fat & $77.60 \pm 0.958$ & $74.82 \pm 0.958$ & * \\
\hline FFDM & $6.97 \pm 0.250$ & $7.60 \pm 0.250$ & * \\
\hline Moisture & $15.42 \pm 0.989$ & $17.5 \pm 0.989$ & * \\
\hline \multicolumn{4}{|l|}{ Fatty acids and ratios } \\
\hline $14: 0$ & $1.58 \pm 0.023$ & $1.60 \pm 0.023$ & NS \\
\hline $15: 0$ & $0.02 \pm 0.007$ & $0.05 \pm 0.007$ & $* *$ \\
\hline $16: 0$ & $29.71 \pm 0.195$ & $28.60 \pm 0.195$ & $* * *$ \\
\hline $16: 1 c 9$ & $2.00 \pm 0.083$ & $2.09 \pm 0.083$ & NS \\
\hline $17: 0$ & $0.42 \pm 0.020$ & $0.54 \pm 0.020$ & $* * *$ \\
\hline $18: 0$ & $14.25 \pm 0.378$ & $13.72 \pm 0.378$ & NS \\
\hline $18: 1 t 9$ & $0.053 \pm 0.005$ & $0.048 \pm 0.005$ & NS \\
\hline $18: 1 c 9$ & $37.28 \pm 0.358$ & $37.10 \pm 0.358$ & NS \\
\hline $18: 1 c 7$ & $2.35 \pm 0.058$ & $2.51 \pm 0.058$ & NS \\
\hline $18: 2 c 9,12(n-6)$ & $11.13 \pm 0.256$ & $12.44 \pm 0.256$ & $\star *$ \\
\hline $20: 0$ & $0.20 \pm 0.007$ & $0.18 \pm 0.007$ & * \\
\hline $18: 3 c 9,12,15(n-3)$ & $0.48 \pm 0.030$ & $0.54 \pm 0.030$ & NS \\
\hline $20: 2 c 11,14(n-6)$ & $0.37 \pm 0.009$ & $0.38 \pm 0.009$ & NS \\
\hline $20: 3 c 11,14,17(n-3)$ & $0.01 \pm 0.006$ & $0.03 \pm 0.006$ & $\star *$ \\
\hline $20: 4 c 5,8,11,14(n-6)$ & $0.13 \pm 0.008$ & $0.17 \pm 0.008$ & $* * *$ \\
\hline SFA & $46.58 \pm 0.517$ & $44.68 \pm 0.517$ & * \\
\hline MUFA & $41.69 \pm 0.457$ & $41.74 \pm 0.457$ & NS \\
\hline PUFA & $12.13 \pm 0.282$ & $13.58 \pm 0.282$ & $* \star *$ \\
\hline$n-6$ & $11.68 \pm 0.270$ & $13.00 \pm 0.270$ & $* *$ \\
\hline$n-3$ & $0.49 \pm 0.029$ & $0.57 \pm 0.029$ & * \\
\hline PUFA:SFA & $0.26 \pm 0.008$ & $0.31 \pm 0.008$ & $\star *$ \\
\hline$n-6: n-3$ & $24.40 \pm 1.250$ & $23.54 \pm 1.250$ & NS \\
\hline
\end{tabular}

Significance level: ${ }^{*} P<0.05,{ }^{* *} P<0.01,{ }^{* \star *} P<0.001$, NS: not significant.

FFDM: fat-free dry matter, SFA: total saturated fatty acids, MUFA: total monounsaturated fatty acids, PUFA: total polyunsaturated fatty acids, $n-6$ : total omega- 6 fatty acids, n-3: total omega-3 fatty acids, $c$ : cis, PUFA: SFA: ratio of polyunsaturated fatty acids and saturated fatty acids, $n-6: n-3:$ ratio of $n-6: n-3$.

Previous studies have shown that dietary $n-6: n-3$ ratio affects the fatty acid profile of the resultant muscle and fat tissues (Huang et al., 2008; Li et al., 2015). A high n-6: n-3 proportion is undesirable for consumer health. However, various lines of evidence in the literature favour the importance of the n-6:n-3 ratio, and support the view that decreasing it through dietary manipulation leads to increased protection against degenerative diseases (Russo, 2009). The MUFA proportions in LW and WS pigs were above the range highlighted by Hoffman et al. (2004). Ideal MUFA reduces human low density lipoprotein (LDL) cholesterol and increases high density lipoprotein ( $\mathrm{HDL}$ ) cholesterol concentrations and lower the risk of coronary heart disease (Department of Health, 1994).

\section{Conclusions}

Overall, the study showed preferential attributes of pork from LW gilts than from WS gilts. Fatty acid profiles showed that there is a need to manipulate the feed given to pigs so that pork can be of good 
nutritional value to the consumer. Further research should assess the physico-chemical attributes and fatty acid profiles of pig breeds when fed on forage-based diets.

\section{Acknowledgements}

The authors are grateful to the Govan Mbeki Research and Development Centre at the University of Fort Hare for funding this research. Thanks to Adelaide Municipal Abattoir for slaughtering and vacuum packing pork samples.

\section{Authors'Contributions}

$\mathrm{JM}$ and $\mathrm{MC}$ were involved in the proposal development and funding of the project while AGB and CLFK were involved in management of the pigs until slaughter. VM was the expert in meat science analysis and $\mathrm{AH}$ was the expert in fatty acids analysis. All the authors were involved in the write up of the final paper.

\section{Conflict of Interest Declaration}

All authors declare that there are no actual or potential conflicts of interest between the authors and other people or organizations that could inappropriately bias their work.

\section{References}

Association of Analytical Chemists, 2005. Official methods of analysis. (18 $8^{\text {th }}$ ed.). Washington, DC.

Bester, J., 2010. The indigenous pig in South Africa, Blackwell, Pretoria, South Africa.

Chimonyo, M., Bhebhe, E., Dzama, K., Halimani, T.E. \& Kanengoni, A. 2005. Improving smallholder pig production for food security and livelihood of the poor in Southern Africa. African Crop Science Conference Proceedings 7, 569573.

Chimonyo, M., Dzama, K. \& Mapiye, C., 2010. Growth performance and carcass characteristics of indigenous Mukota pigs of Zimbabwe. Trop. Anim. Health Prod. 42 (5), 1001-1007.

Christie, W.W., Sébédio, J.L. \& Juanéda, P., 2001. A practical guide to the analysis of conjugated linoleic acid. Inform. $12,147-152$.

Department of Health, 1994. Nutritional aspects of cardiovascular disease. Report on Health and Social Subjects; No. 46, London.

Dilger, A.C., Rincker, P.J., Eggert, J.M., Mckeith, F.K. \& Killefer, J., 2010. Pork tenderness and post-mortem tenderization: Correlations with meat quality traits and the impact of sire line. J. Muscle Foods 21 (3), 529-544.

Enser, E., Hallett, K., Hewitt, B., Fursey, G.A.J. \& Wood, J.D., 1996. Fatty acid content and composition of English beef, lamb and pork at retail. Meat Sci. 42 (4), 443-456.

FAOSTAT, 2012. Food and Agricultural Organization of the United Nations, Rome, Italy. http://faostat.fao.org/site/569/default.aspx.

Folch, J., Lees, M. \&Sloane-Stanley, G.H., 1957. A simple method for the isolation and purification of total lipids from animal tissue. J. Biol. Chem.226, 497-509.

Gentry, J.G., Miller, M.F. \& McGlone, J.J., 2001. Alternative production systems: Influence on pig growth and pork quality. Second International Virtual Conference on Pork Quality. pp. 1-7.

Halimani, T.E., Muchadeyi, F.C., Chimonyo, M. \& Dzama, K., 2010. Pig genetic resource conservation: The Southern African perspective. Ecol. Econ. 69 (5), 944-951.

Hoffman, L.C., Styger, E., Muller, M. \& Brand, T.S., 2004. The growth and carcass and meat characteristics of pigs raised in a free-range or conventional housing system. S. Afr. J. Anim. Sci. 33, 166-175.

Hoffman, L.C., Styger, W.F., Brand, T.S. \& Muller, M., 2005. The growth, carcass yield, physical and chemical characteristic of two South African indigenous pig breeds. S. Afr. J. Anim. Sci. 6, 25.

Huang, F.R., Zhan, Z.P., Luo, J., Liu, Z.X. \& Peng, J., 2008. Duration of dietary linseed feeding affects the intramuscular fat, muscle mass and fatty acid composition in pig muscle. Livest. Sci. 118, 132-139.

Hugo, A. \& Roodt, E., 2015. Fat quality of South African pigs with different carcass classification characteristics. S. Afr. J. Anim. Sci. 45, 3.

Lawrie, R.A.,1998. Meat Science. 6th edition. CRC, Abington, England. pp. 143-244.

Li,F., Duan, Y., Li, Y., Tang, Y., Geng, M., Oladele, O.A., Kim, S.W. \& Yin, Y., 2015. Effects of dietary n-6 : n-3 PUFA ratio on fatty acid composition, free amino acid profile and gene expression of transporters in finishing pigs. Br. J. Nutr. 113, 739-748.

Li, Y.X., Cabling, M.M., Kang, H.S., Kim, T.S., Yeom, S.C., Sohn, Y.G., Kim, S.H., Nam, K.C.\& Seo, K.S., 2013. Comparison and correlation analysis of different swine breed meat quality. Asian Australas .J. Anim. 26, 905-910.

Muchenje, V., Dzama, K., Chimonyo, M., Strydom, P.E., Hugo, A. \& Raats, J.G., 2009. Some biochemical aspects pertaining beef eating quality and consumer health: A review. Food Chem. 112, 279-289.

Nour, A.Y.M., Gomide, L.A., Mills, E.W., Lemenager, R.P. \& Judge, M.D., 1994. Influence of production and post-mortem technologies on comparison and palatability of USDA select grade beef. J. Anim. Sci. 72, 1081-1386.

Renaudeau, D. \& Maurot, J., 2007. A comparison of carcass and meat quality characteristics of Creole and Large White pigs slaughtered at $90 \mathrm{~kg} \mathrm{BW}$. Meat Sci. 76, 165-171.

Renaudeau, D., Hilaire, M. \& Mourot, J., 2005. A comparison of carcass and meat quality characteristics of Creole and Large White pigs slaughtered at 150 days of age. Anim. Res. 54, 43-54.

Russo, G.L., 2009. Dietary $n-6$ and $n-3$ polyunsaturated fatty acids: from biochemistry to clinical implications in cardiovascular prevention. Biochem. Pharmacol. 77, 937-946. 
Statistical Analysis Systems (SAS). 2008. SAS/STAT User's Guide, Release 9.1.3. SAS Institute Inc, Cary, North Carolina, USA.

Terlouw, C., Berne, A. \& Astruc, T., 2009. The effect of rearing and slaughter conditions on behaviour, physiology and meat quality Large White and Duroc sired pigs. Livest. Sci. 122(2-3), 199-213.

Van der Westhuizen, L., 2011. South Africa's pork price may drop 15\% on export ban due to foot-and-mouth. http://www.bloomberg.com/news/2011-03-03/south-africa-s-pork-price-may-drop-15-on-export-ban-due-to-footand-mouth.html.

Van Oeckel, M.J., Warnants, N. \& Boucque, C.V., 1999. Pork tenderness estimation by taste panel, Warner-Bratzler shear force and on-line methods. Meat Sci. 53, 259-267.

Warnants, N., Van Oeckel, M.J. \& De Paepe, M., 2001. Fat in pork- Dietary modification and pork quality. Pig News Infor. $22(4), 107-113$.

Wheeler, T.L. \& Young, L.D., 1992. Meat palatability of Duroc and Chinese first-cross barrows. J. Food Sci. 57 (3), $794-$ 795.

Wood, J.D., Enser, M., Fisher, A.V., Nute, G.R., Sheard, R.I., Richardson, R.I., Hughes, S.I. \& Whittington, F.M., 2008. Fat deposition, fatty acid composition and meat quality: A review. Meat Sci. 78, 343-358.

Yu, L.H., Lee, E.S., Jeong, J.Y., Paik, H.D., Choi, J.H. \& Kim, C.J. 2005. Effects of thawing temperature on the physicochemical properties of pre-rigor frozen chicken breast and leg muscles. Meat Sci. 71, 375-382. 